\title{
WebGIS as boundary tools between scientific geoinformation and disaster risk reduction action in volcanic areas
}

\author{
G. Le Cozannet ${ }^{1,2}$, M. Bagni ${ }^{3}$, P. Thierry ${ }^{1}$, C. Aragno ${ }^{3}$, and E. Kouokam ${ }^{4}$ \\ ${ }^{1}$ BRGM/French Geological Survey - Risk and Prevention Department, 3 avenue Claude Guillemin, 45060 Orléans, France \\ ${ }^{2}$ Université Paris 1 Panthéon-Sorbonne/Laboratoire de Géographie Physique, CNRS - UMR8591, Paris, France \\ 3'KELL s.r.1., Via E. Q. Visconti, 8, 00193 Roma, Italy \\ ${ }^{4}$ Ministry of Industry, Mines and Technological Development, Yaoundé, Cameroon \\ Correspondence to: G. Le Cozannet (g.lecozannet@brgm.fr)
}

Received: 25 July 2013 - Published in Nat. Hazards Earth Syst. Sci. Discuss.: 22 October 2013

Revised: 10 May 2014 - Accepted: 15 May 2014 - Published: 25 June 2014

\begin{abstract}
As the amount of spatial data is growing, there is increased interest in developing tools to explore, visualize and interpret them, with the final aim of informing decision making efficiently. Within the European MIAVITA project, we examined this issue in the case of volcanic areas, where existing geospatial databases are particularly complex due to the number of threats to be considered, including volcanic (e.g. lava flows, ash fall) and non-volcanic hazards, such as landslides or tsunamis. We involved a group of hazard and risk analysts and managers, civil security officers, GIS analysts and system developers to design a Web-based geographical information system (WebGIS). We tested the system at the Mount Cameroon volcano, taking advantage of a complex hazard and risk geographical database. This study enabled identifying key requirements for such tools in volcanic areas, such as the need to manage user privileges differently according to their profile and the status of the volcano. This work also highlights that, in addition to the development of large geoinformation clearinghouses, there is a need for sitespecific information systems focused on working procedures of users, in order to fill the last gap between data producers and users.
\end{abstract}

\section{Introduction}

An important challenge to deal with disaster risk reduction is to connect management and decision-making practices with scientific and technical knowledge in an efficient way. To achieve this aim, one of the strategies consists in users and scientists co-producing common knowledge and "boundary objects" (Cash et al., 2003). Risk is a measure of the expected probability of damage induced by adverse events. Risk therefore combines the multiple relevant hazards in a given area, of the exposed assets, their vulnerability and of the capacity of societies to cope with these hazards (e.g. Marzocchi and Woo, 2009; Alberico et al., 2011). Boundary objects in volcanic risk management include, for example, scenarios and hazard and risk maps (e.g. Thierry et al., 2008; Felpeto et al., 2007), as well as tools such as geographical information systems (GISs) to disseminate this material (Pareschi et al., 2000).

Owing to recent technological developments, Web-based cartography has now reached maturity for disseminating the heterogeneous hazard and risk geographical information (e.g. Müller et al., 2006; Douglas et al., 2008). Consequently, numerous WebGIS tools have been developed for disseminating data and information relevant for volcanic hazard assessment. For example, the Globvolcano (http://www. globvolcano.org/) and EVOSS tools (Tait and Ferrucci, 2013) provide Earth-observation-based services aimed at monitoring volcanic natural phenomena. The tool developed within the HOTVOLC project disseminates remote-sensing information on volcanic ash clouds in near real time (Labazuy et al., 2012). One important application of this tool is the management of volcanic ash crises and the associated threats for aircraft navigation. Finally, the Lav@ hazard tool (Vicari et al., 2011) is focused on the production of services based on remote sensing products and lava-flow scenarios. Such tools have considered the needs of the users and have proven useful 


\begin{tabular}{|c|c|c|c|c|}
\hline & $\begin{array}{l}\text { Prevention and } \\
\text { mitigation }\end{array}$ & Preparedness & Response & Recovery \\
\hline Critical needs & $\begin{array}{c}\text { Reducing hazard, } \\
\text { vulnerability, exposure }\end{array}$ & $\begin{array}{l}\text { Getting prepared to } \\
\text { response \& recovery }\end{array}$ & $\begin{array}{c}\text { Crisis and emergency } \\
\text { management }\end{array}$ & $\begin{array}{l}\text { Reconstruction and } \\
\text { restauration of services }\end{array}$ \\
\hline $\begin{array}{l}\text { Potential use of } \\
\text { Web-based ha- } \\
\text { zard and risk GIS } \\
\text { systems in the } \\
\text { case of the MIA- } \\
\text { VITA volcanoes }\end{array}$ & $\begin{array}{l}\text { Provision of simple } \\
\text { access to hazard and risk } \\
\text { information for hazard, } \\
\text { vulnerability or exposure } \\
\text { assessment and for local } \\
\text { or regional planning }\end{array}$ & $\begin{array}{l}\text { Identification of critical } \\
\text { infrastructures and } \\
\text { networks during crisis } \\
\text { and of possible needs } \\
\text { (e.g., evacuation } \\
\text { procedures) }\end{array}$ & $\begin{array}{l}\text { Indentification of critical infras- } \\
\text { tructures for the response (e.g. } \\
\text { for use as temporary shelters) } \\
\text { and updates regarding the crisis } \\
\text { evolution (need of near real } \\
\text { time services) }\end{array}$ & $\begin{array}{l}\text { Provision of information for } \\
\text { local or regional planning } \\
\text { (requires update of the } \\
\text { hazard assessment) }\end{array}$ \\
\hline $\begin{array}{c}\text { Relevance of } \\
\text { hazard and risk } \\
\text { WebGIS system }\end{array}$ & Very high & High & $\begin{array}{l}\text { Low (priority should be given to } \\
\text { existing robust procedures or } \\
\text { systems) }\end{array}$ & High \\
\hline
\end{tabular}

Figure 1. Disaster management cycle and the potential use of a Web-based GIS information system throughout the different phases of the cycle. In the case of the MIAVITA volcanoes (Mt Cameroon in Cameroon; Fogo in Cape Verde; Merapi in Indonesia and Kanlaon in the Philippines), it was agreed that such a system would be most relevant in support of the prevention and mitigation phases (long-term anticipation of a potential crisis). However, provided information on critical infrastructures and their utility during the crisis, response and recovery phases is made available (e.g. potential for a recreational area to serve for sheltering displaced people). Therefore, the relevance of the system for preparedness (shorter-term anticipation of the crisis), the response and recovery has also been considered as high.

to assess the threats induced by volcanic processes and to take appropriate measures to prevent or manage a crisis.

All these tools share a common feature: their design was organized around key modelling tools or Earth observation systems. This can be explained by the fact that their inception either started from the researchers' knowledge or from the experience of leading users who had an early understanding of the potential benefits from technological solutions. In their analysis of user involvement methods, Steen et al. (2007) recognize that this approach is efficient in achieving rapid results. However, they also suggest that an approach based on the analysis of user knowledge and workflows can also stimulate new practices in the long term. Here, we analysed existing and potential use cases of geographical information with a group of stakeholders involved in risk management in volcanic areas, and we designed a Web-based GIS system for the management and visualization of volcanic hazard and risk information accordingly (Sect. 2). We tested the system at Mount Cameroon using an existing set of hazard and risk geographical data. This experience provides insights for integrating such hazard and risk geospatial tools within current risk management practices in volcanic areas (Sect. 3), as well as for linking the development of large geoinformation infrastructures and services with users (Sect. 4).

\section{User-workflow-oriented WebGIS: principles, requirements and tool developed}

In order to take into account the workflows of targeted users (Culshaw et al., 2006), we gathered a group of stakeholders composed of users of geoinformation (volcanoes observatories scientists, hazard and risk analysts and managers and civil security officers) as well as GIS specialists and system developers. This group brought together about 12 persons involved in prevention, preparedness and crisis management of volcanoes in Cameroon, Cape Verde, Philippines and Italy. Our method for designing the tool is a combination between co-design and emphatic design (Steen et al., 2007): co-design refers to a process in which users and system designers elaborate a system together; emphatic design requires system developers to share the experience of end users to create a system adapted to their workflows. We first organized workshops to envision idealized geospatial information dissemination and management practices. Then, following the approach of Darke and Shanks (1997), we formalized progressively the data and workflows to finally design an evolving prototype, which was improved, tested and validated by a broad range of potential users involved in the MIAVITA project.

Through this method, the group identified key requirements for a risk and hazard GIS data repository. A territorial GIS risk repository should contain, at least, a multi-hazard map (e.g. Kappes et al., 2012; Neri et al., 2013), an inventory 
of exposed elements together with attributes such as their physical vulnerability or their importance during disaster crisis or recovery, and the associated risk maps. From the risk management perspective, the completeness of data is even more important than the detailed accuracy of a particular data set. Therefore, all hazards and types of assets at risk in a given territory should be addressed. The tool should also consider the most critical aspects of hazard and risk information dissemination across the different phases of disaster management (Fig. 1): for example, during the prevention and mitigation phases, critical needs are to reduce the vulnerability and exposure of populations and assets. In some cases, the hazard can be reduced as well (e.g. some landslide-prone area can be stabilized). Here, the critical needs for information are hazard and risk maps: the first can support decision making regarding new settlement or land use policies; the second enable to evaluate the expected damages for maximizing the impacts of risk reduction actions. Similar information needs can be identified for the preparedness, response and recovery phases, in particular regarding the identification of critical assets for evaluation and sheltering, as well as updated hazard maps to enable reconstruction. All these products represent a large number of geographical layers and of possible relevant combinations. Therefore, flexible data management options and data models, as well as clear roles and responsibilities in data-flow management procedures, are needed. Finally, different versions of each data set can exist, such as for example a preliminary version of a hazard map, not yet approved by authorities. Here, a generic procedure to manage the different levels of maturity of the various data sets has been elaborated. We developed the procedure provided in Fig. 2, which is flexible enough to apply to any of the MIAVITA volcanoes.

Thereafter, the group identified key situations where a WebGIS has an added value to disseminate this geospatial information compared to other existing solutions. Firstly, a paper atlas is not an appropriate option to provide and exhaustive view of all relevant hazard and risk maps, simply because there are too many possible combinations of data layers. Secondly, while a stand-alone GIS application may resolve the previous difficulty, existing GIS tools remain specialized tools and many potential users are unfamiliar with them. Finally, as a growing amount of geographical resources is being made available from multiple sources (see e.g. the Earth observation data disseminated through the Global Earth Observation System of Systems (GEOSS), which is under development, Percivall et al., 2013), the group envisioned that incorporating interoperability features in the system should reinforce its ability to manage new data, thus increasing its sustainability. This supported the idea that, beside more specialized tools for managing geo-information databases or designing eruption scenarios (e.g. Gehl et al., 2013), an interoperable Web-based tool is required to facilitate the visualization, by non-GIS experts, of complex hazard and risk databases (Salvi et al., 1999). Functionalities for updating the data layers through the WebGIS application were not consid- ered to be a priority here. There are however no technical barriers to developing such editing tools: for example, Huang et al. (2013) provide an example of a landslide database and WebGIS that incorporates the possibility of updating and editing the landslide inventory.

As no solution incorporating all the features listed above was available at the time of the project, we developed a new tool using open source libraries such as OpenLayers, GeoExt and ExtJS. The final tool incorporates two user interfaces (Fig. 3): (1) the browsing component, which is commonly referred to as a WebGIS; and (2) the database and user profile management interface. The WebGIS architecture itself includes four interdependent subsystems. This subsystems are the following: (1) a Web server; (2) an authentication, authorization and audit server, which provides security services aimed at applying the access and control rules; (3) a GIS publisher enabling the final data provisioning and distribution; and (4) repositories that includes applications requested to configure the GIS repository and the authentication, authorization and audit server. For reinforcing reliability, each component can be hosted on an independent platform and repositories can be hosted on high-availability infrastructure that goes from a redundant array of independent disks (RAID) of type 1 (mirroring without parity or striping) up to a RAID of type 5 (block-level striping with distributed parity) architecture.

\section{Lessons learnt from the Mount Cameroon: usefulness and transportability of the WebGIS}

The volcanic site for testing the capabilities of the system is Mount Cameroon (Fig. 4). The different volcanic, ground instability and tectonic hazard and risk associated with Mount Cameroon have been extensively described by Thierry et al. (2008). This work was based on a regional-scale geological mapping, including on the slopes and summit of the volcano. Moreover, an inventory of exposed elements was undertaken. This study highlighted the multiplicity of hazards affecting this area. In addition to hazards directly linked with eruptions such as lava flows, tephra fall, gas, lahars, ground motions and tsunamis, they showed that the risks associated with landslides were as important as those due to eruptions. In particular, the area east of Limbe is under very high hazard. An important finding of this study was the significant exposure of the towns of Limbe and, to a lesser extent, Buea to geological hazards. In the context of our study, the main point is that all the findings of Thierry et al. (2008) have been incorporated into a GIS database, which we used to test and validate our tool. The GIS database contains geographical layers describing the exposure and elements at risks as well as their strategic importance, single-hazard and multihazard maps, "risk maps" (which actually consist of hazard maps superimposed with the assets vulnerable to these assets), topographic maps, other background information such 


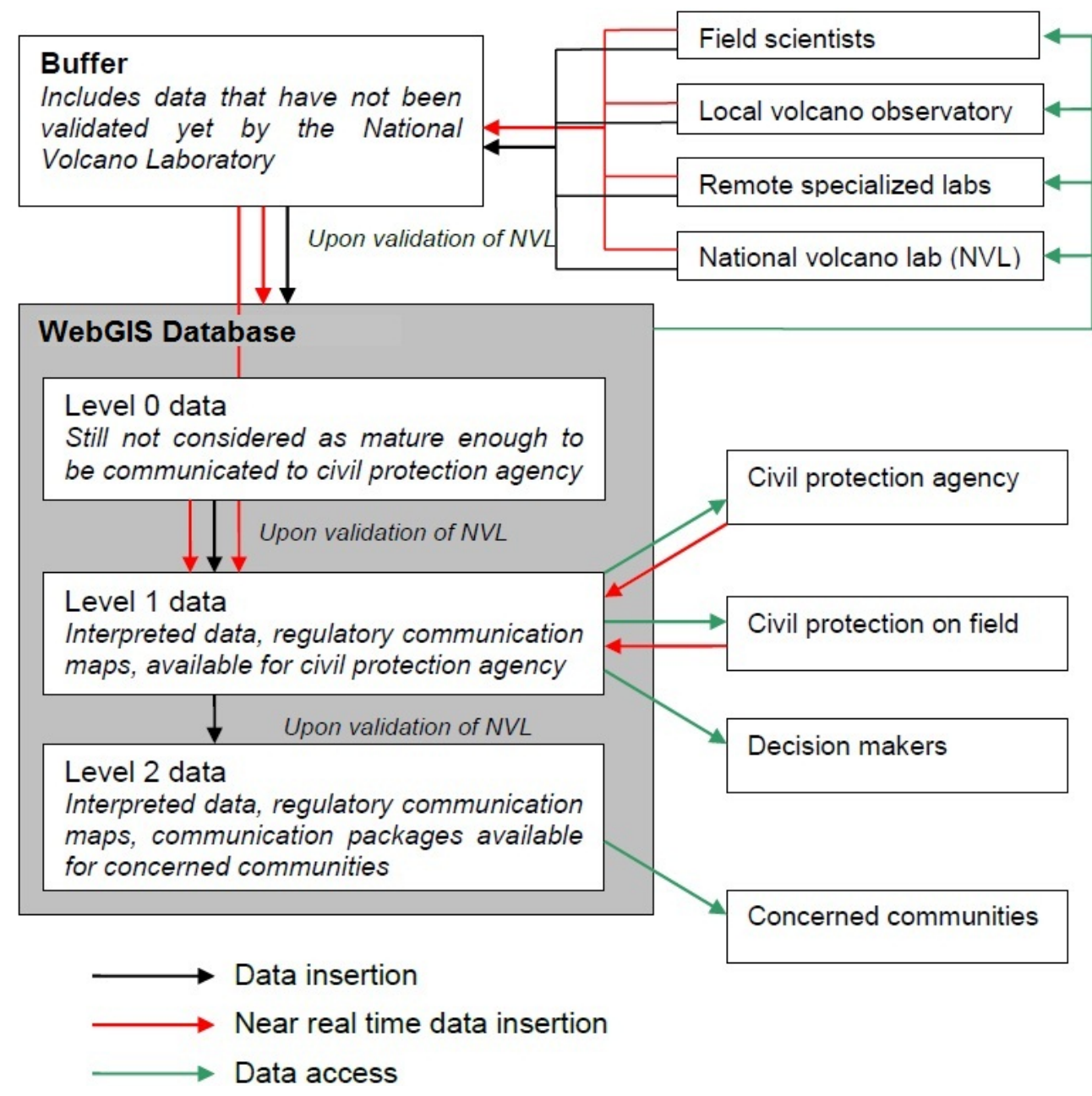

Figure 2. Use-case scheme of information flows between the database management system, data providers and users. This scheme shows the different possibilities for data insertion, validation and access. All data providers are also considered as potential users of the system. Here, a key role is given to the National Volcano Laboratory in managing the information flow.

as optical satellite data and the geological map. Owing to the extensiveness of this database, we could use this case study to develop a controlled vocabulary describing the content of the hazard and risk geographical database and organized in a hierarchical form (i.e. a taxonomy; see Fig. 5). This taxonomy was reviewed by users and provided to the system developer as an example for the first implementation of the system. It covers all geographical data sets presently used in risk management practices in the MIAVITA volcanoes, and adjustments to this taxonomy can be incorporated as whished by the users through the data management interface. This demonstrates the potential transportability of the system to other volcanoes.

Once data have been uploaded to the system, the application enables the visualization of hazard maps together with stake at risk (e.g. water supply network, strategic buildings, roads, etc.) and, owing to interoperability features, other geographical resources located elsewhere such as satellite im- ages made available by Google. Figure 6 shows screenshots of the two Web interfaces (visualization and data management). The WebGIS application was found rather easy to use by a board of users who tested the tool. This testing confirmed that the tool is able to manage any kind of hazard and risk information in an organized way, to display it simply and to manage priorities among the different users during the prevention, preparedness and crisis phases.

The potential of using the WebGIS during the different phases of disasters was discussed with the initial group of users. It was found that the system is able to display the key anticipated scientific and regulatory information in support to prevention and recovery (maps of elements at risks and regulatory hazard and risk maps), preparedness (pre-determined hazards or risk scenarios aiming at testing the response capabilities), crisis management and response (maps of strategic infrastructures for the evacuation of people and for sustaining life in non-evacuated areas and possibly near-real-time 


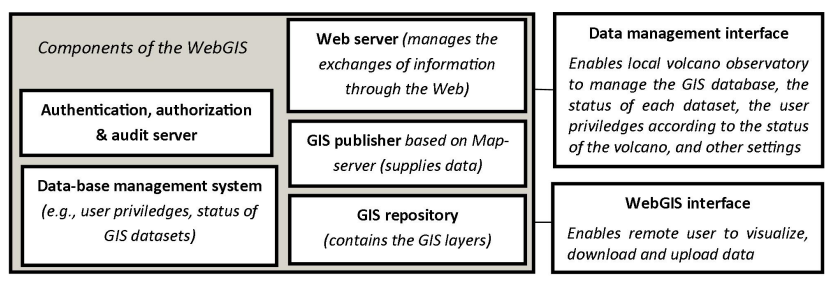

Figure 3. Scheme of the WebGIS application and architecture developed within this study. The GIS database can be visualized through the WebGIS interface. GIS data can be uploaded and managed through the data management interface, through which each user receives privileges that are a function of the status of the volcano (here: inactive, moderate activity and eruption). The WebGIS itself is divided in several components: one Web server manages the exchanges of information through the Web; one authentication authorization \& audit server provides security services (e.g. ensuring that each user receives the relevant privileges according to the status of the volcano); the GIS publisher is the component that finally supplies the data; finally, the GIS database and the rules are stored in the database management system, which is the repository of authentication, authorization and audit rules defined through the data management interface.

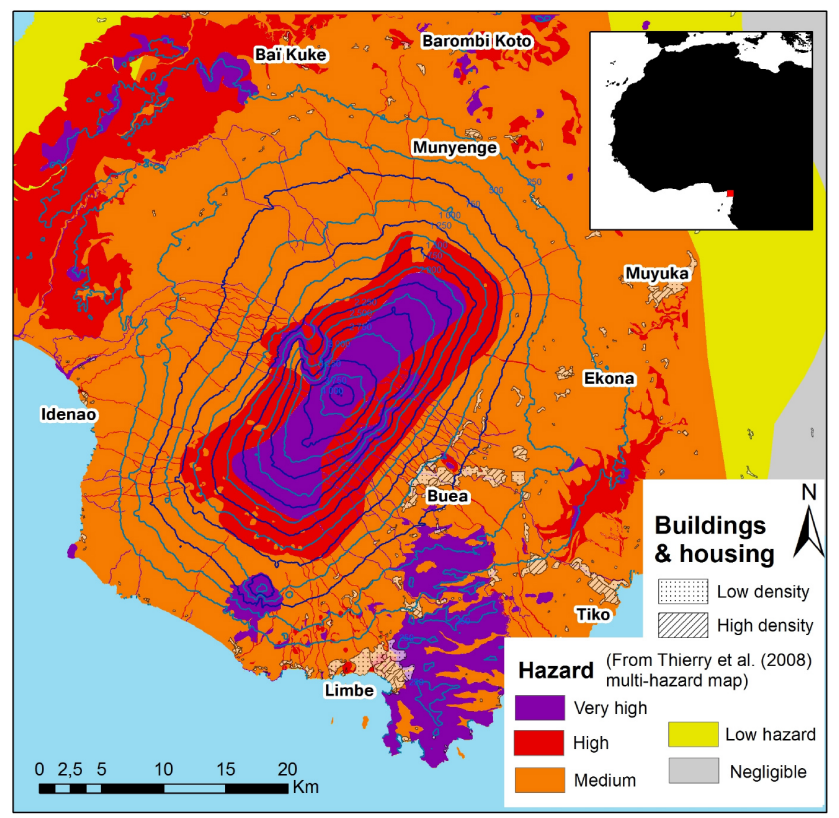

Figure 4. Map of Mount Cameroon showing the multi-hazard map (Thierry et al., 2008), topographical isolines (bins of $250 \mathrm{~m}$ ) and the location of main towns. This hazard maps combines threats due to lava flows, ground instability, ash fall, tsunamis and earthquakes. The map highlights that besides volcanic hazards, the hilly areas in the east of Limbe are subject to very high hazard of landslides.

information provided by field civil security agents or scientists informing about the ongoing volcanic activity and security operations).

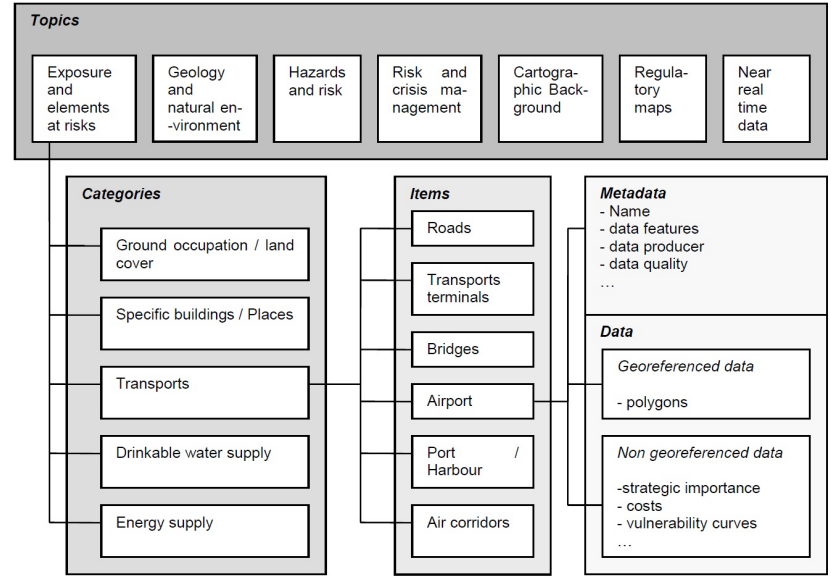

Figure 5. Extract of the taxonomy (i.e. controlled vocabulary organized in a hierarchical form) describing the content of the hazard and risk geographical database.

We acknowledge that there are barriers to the operational use of such a tool. First, the database and user profile management interface still requires GIS and IT skills to be managed, in particular on open source development environment for building spatial internet applications (here: MapServer), on relational database management system (here: MySQL) and on cartographic projections libraries (here: ExtJS, OpenLayers and QuantumGIS). Furthermore, in socially, economically and/or technologically disadvantaged volcanic areas, the range of potential users remains limited. This is especially true in the case of Mount Cameroon. In this context of strong social vulnerability (Apa et al., 2012), the WebGIS has less potential to be useful for people at risk than for national and local authorities concerned with risk management. For local communities at risk, other tools are more appropriate such as participatory 3-D maps (P3DM) for local communities (Cadag and Gaillard, 2012). In fact, while there are examples of WebGIS serving as collaborative decision support tool involving a wide range of users (e.g. Boroushaki and Malczewski, 2010), our application remains primarily targeted to an audience of decision makers, scientists and civil security already familiar with IT, although not necessarily with GIS. For this use case, the application was judged beneficial during the validation phase, and other members of the stakeholder's group requested copies of the system for their own implementation plans at volcanoes in the Philippines and at Fogo (Cape Verde).

Finally, this application at Mount Cameroon confirms that the approach focused on users' existing and potential workflows, although recognized a long process (Steen et al., 2007; Nies and Pelayo, 2010), is necessary to improve existing hazard and risk geoinformation management practices. It demonstrates that this type of boundary object is potentially efficient in facilitating mutual exchange of knowledge between science and disaster risk reduction (Cash et al., 2003). 

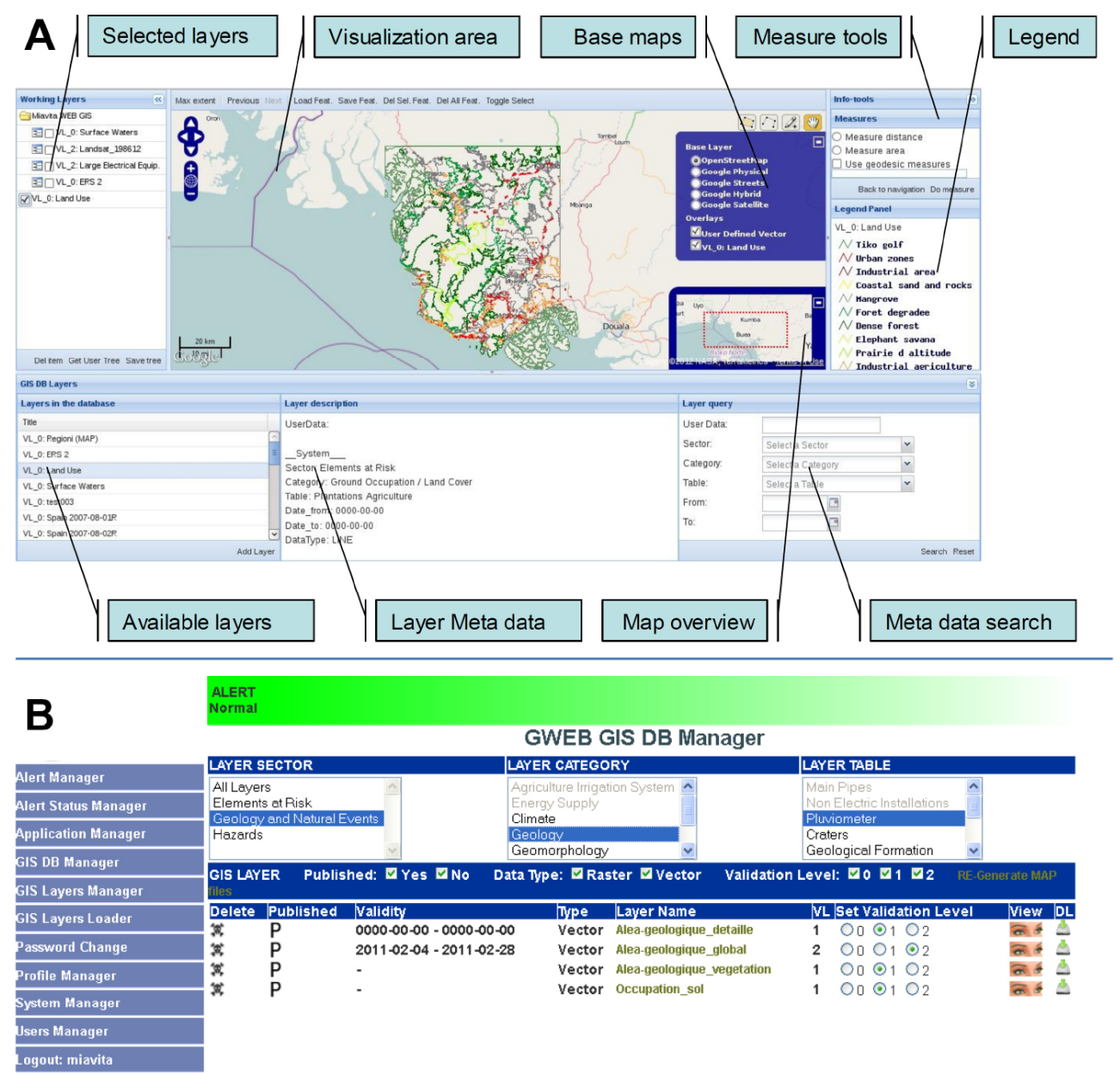

Figure 6. (A) represents the end user's Web interface running on a standard Web browser. Different areas of the screen can be folded to give more space to the GIS central visualization area. The users can search the GIS database using the meta-information stored along with the geographical data - screen bottom three panels. The selected GIS layers can be saved as independent scenarios and later retrieved from the server, as well as user's vector features (polygons, lines and points) can be added to the visualization area, saved on the server for further use and shared with the other WebGIS users. (B) shows the server GIS layer manager component. This module allows the management of all the GIS data contained in the database, including the promotion/demotion of the "validation level" associated with each GIS layer. On the left side the system shows all the management modules that allow the management and configuration of the whole system, including the switch from one alert level to another. Each alert level can be independently configured giving GIS data access priority to the more appropriate users in case of emergency.

\section{Conclusions}

Many efforts are currently focusing on developing large geoinformation architectures and services based on modelling tools or Earth observation instruments, in particular through GEOSS (e.g. Hollingsworth et al., 2005; Percivall et al., 2013; Plag et al., 2012). The development of these systems remains fundamentally driven by new scientific and technological developments. Here, we started from the procedures that use spatial information in risk management to design a Web-based application for managing and displaying a complex geographical database dedicated to hazard and risks in volcanic areas. We applied and tested the application for Mount Cameroon; other volcano observatories requested copies of the tool. Importantly, current interoperability features make it possible to visualize locally owned data layers together with the remote geoinformation provided through large geoinformation infrastructures. This practical example shows that there is a high complementarity between technologically based geoinformation architectures and services such as GEOSS and systems based on user workflows. The first requires shorter development cycles and provides access to generic services applicable for a large range of users, and the second stimulates the integration of a large range of spatial information and data within existing and potential users' procedures in the long term. This study therefore encourages the development of spatial information systems dedicated 
to specific sites, sectors or procedures, to complement the GEOSS architecture and ensure its connection with users.

Acknowledgements. This study was undertaken as part of the MIAVITA project (financed by the European Commission under the 7th Framework Programme for Research and Technological Development, Area "Environment", Activity 6.1 "Climate Change, Pollution and Risks") and of the BRGM 'Multirisk' programme (Prg 25). We thank a group of experts who participated to the design of the WebGIS. Particular thanks are owed to A. Salvati, A. Canestro, F. Doumaz, C. Christiani, V. Bosi, L. Colini, J. Loiseau, B. Faria, J. Berger, A. Daag, R. Solidum and C. Bignami for their most active participation. J. Douglas proofread a draft.

Edited by: M. Neri

Reviewed by: L. Becerril, V. Bosi, and three anonymous referees

\section{References}

Alberico, I., Petrosino, P., and Lirer, L.: Volcanic hazard and risk assessment in a multi-source volcanic area: the example of Napoli city (Southern Italy), Nat. Hazards Earth Syst. Sci., 11, 10571070, doi:10.5194/nhess-11-1057-2011, 2011.

Apa, M. I. P., Kouokam, E., Akoko, R. M., Nana, C., and Buongiorno, M. F.: An ethnical approach to socio-economic information sources in ongoing vulnerability and resilience studies: the Mount Cameroon case, Ann. Geophys., 55, 393-399, doi:10.4401/ag-5569, 2012.

Boroushaki, S. and Malczewski, J.: Measuring consensus for collaborative decision-making: A GIS-based approach, Comput. Environ. Urban Syst., 34, 322-332, doi:10.1016/j.compenvurbsys.2010.02.006, 2010.

Cadag, J. R. D. and Gaillard, J. C.: Integrating knowledge and actions in disaster risk reduction: the contribution of participatory mapping, Area, 44, 100-109, doi:10.1111/j.14754762.2011.01065.x, 2012.

Cash, D. W., Clark, W. C., Alcock, F., Dickson, N. M., Eckley, N., Guston, D. H., Jager, J., and Mitchell, R. B.: Knowledge systems for sustainable development, P. Natl. Acad. Sci. USA, 100, 80868091, doi:10.1073/pnas.1231332100, 2003.

Culshaw, M. G., Nathanail, C. P., Leeks, G. J. L., Alker, S., Bridge, D., Duffy, T., Fowler, D., Packman, J. C., Swetnam, R., Wadsworth, R., and Wyatt, B.: The role of web-based environmental information in urban planning - the environmental information system for planners, Sci. Total Environ., 360, 233-245, doi:10.1016/j.scitotenv.2005.08.037, 2006.

Darke, P. and Shanks, G.: User viewpoint modelling: understanding and representing user viewpoints during requirements definition, Inform. Syst. J., 7, 213-239, doi:10.1046/j.1365-2575.1997.d0119.x, 1997.

Douglas, J., Uslaender, T., Schimak, G., Esteban, J. F., and Denzer, R.: An open distributed architecture for sensor networks for risk management, Sensors, 8, 1755-1773, doi:10.3390/s8031755, 2008.

Felpeto, A., Marti, J., and Ortiz, R.: Automatic GIS-based system for volcanic hazard assessment, J. Volcanol. Geotherm. Res., 166, 106-116, doi:10.1016/j.jvolgeores.2007.07.008, 2007.
Gehl, P., Quinet, C., Le Cozannet, G., Kouokam, E., and Thierry, P.: Potential and limitations of risk scenario tools in volcanic areas through an example at Mount Cameroon, Nat. Hazards Earth Syst. Sci., 13, 2409-2424, doi:10.5194/nhess-13-24092013, 2013.

Huang, R., Huang, J., Ju, N., He, C., and Li, W.: WebGISbased information management system for landslides triggered by Wenchuan earthquake, Nat. Hazards, 65, 1507-1517, doi:10.1007/s11069-012-0424-x, 2013.

Hollingsworth, A., Uppala, S., Klinker, E., Burridge, D., Vitart, F., Onvlee, J., De Vries, J. W., De Roo, A., and Pfrang, C.: The transformation of earth-system observations into information of socio-economic value in GEOSS, Q. J. Roy. Meteorol. Soc., 131, 3493-3512, doi:10.1256/qj.05.181, 2005.

Kappes, M. S., Keiler, M., von Elverfeldt, K., and Glade, T.: Challenges of analyzing multi-hazard risk: a review, Nat. Hazards, 64, 1925-1958, doi:10.1007/s11069-012-0294-2, 2012.

Labazuy, P., Gouhier, M., Harris, A., Guehenneux, Y., Hervo, M., Berges, J. C., Freville, P., Cacault, P., and Rivet, S. Near real-time monitoring of the April-May 2010 Eyjafjallajokull ash cloud: an example of a web-based, satellite datadriven, reporting system, Int. J. Environ. Pollut., 48, 262-272, doi:10.1504/ijep.2012.049673, 2012.

Marzocchi, W. and Woo, G.: Principles of volcanic risk metrics: Theory and the case study of Mount Vesuvius and Campi Flegrei, Italy, J. Geophys. Res.-Solid Earth, 114, B03213, doi:10.1029/2008jb005908, 2009.

Müller, M., Vorogushyn, S., Maier, P., Thieken, A. H., Petrow, T., Kron, A., Büchele, B., and Wächter, J.: CEDIM Risk Explorer a map server solution in the project "Risk Map Germany", Nat. Hazards Earth Syst. Sci., 6, 711-720, doi:10.5194/nhess-6-7112006, 2006.

Neri, M., Le Cozannet, G., Thierry, P., Bignami, C., and Ruch, J.: A method for multi-hazard mapping in poorly known volcanic areas: an example from Kanlaon (Philippines), Nat. Hazards Earth Syst. Sci., 13, 1929-1943, doi:10.5194/nhess-13-19292013, 2013.

Nies, J. and Pelayo, S.: From users involvement to users' needs understanding: A case study, Int. J. Medical Inform., 79, E76-E82, doi:10.1016/j.ijmedinf.2009.06.007, 2010.

Pareschi, M. T., Cavarra, L., Favalli, M., Giannini, F., and Meriggi, A.: GIS and volcanic risk management, Nat. Hazards, 21, 361379, doi:10.1023/a:1008016304797, 2000.

Percivall, G. S., Alameh, N. S., Caumont, H., Moe, K. L., and Evans, J. D.: Improving Disaster Management Using Earth Observations-GEOSS and CEOS Activities, IEEE J. Select. Top. Appl. Earth Observ. Remote Sens., 6, 1368-1375, doi:10.1109/jstars.2013.2253447, 2013.

Plag, H. P., Foley, G., Jules-Plag, S., Kaufman, J., Ondich, G., and IEEE: The GEOSS user requirement registry: linking users of GEOSS across disciplines and societal areas, 2012 IEEE Int. Geosc. Remote Sens. Symposium (IGARSS), 3517-3520, 2012.

Salvi, S., Quattrocchi, F., Brunori, C. A., Doumaz, F., Angelone, M., Billi, A., Buongiorno, F., Funiciello, R., Guerra, M., Mele, G., Pizzino, L., and Salvini, F.: A multidisciplinary approach to earthquake research: Implementation of a geochemical Geographic Information System for the Gargano site, southern Italy, Nat. Hazards, 20, 255-278, doi:10.1023/a:1008105621134, 1999. 
Steen, M., Kuijt-Evers, L., and Klok, J.: Early user involvement in research and design projects - a review of methods and practices. 23rd EGOS Colloquium (European Group for Organizational Studies) 5-7 July, 2007, Vienna, 2007.

Tait, S. and Ferrucci, F.: A Real-Time, Space Borne Volcano Observatory to Support Decision Making During Eruptive Crises: European Volcano Observatory Space Services, Uksim-Amss 15th International Conference on Computer Modelling and Simulation (Uksim 2013), 283-289, doi:10.1109/UKSim.2013.121, 2013.
Thierry, P., Stieltjes, L., Kouokam, E., Ngueya, P., and Salley, P. M.: Multi-hazard risk mapping and assessment on an active volcano: the GRINP project at Mount Cameroon, Nat. Hazards, 45, 429456, doi:10.1007/s11069-007-9177-3, 2008.

Vicari, A., Bilotta, G., Bonfiglio, S., Cappello, A., Ganci, G., Herault, A., Rustico, E., Gallo, G., and Del Negro, C.: LAV@HAZARD: a web-GIS interface for volcanic hazard assessment, Ann. Geophys., 54, 662-670, doi:10.4401/ag-5347, 2011. 